\title{
Schistosomiasis-associated pulmonary arterial hypertension: a systematic review
}

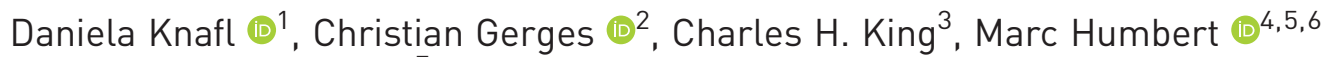 \\ and Amaya L. Bustinduy ${ }^{7}$
}

Affiliations: ${ }^{1}$ Dept of Internal Medicine III, Division of Nephrology and Dialysis, Medical University of Vienna, Vienna, Austria. ${ }^{2}$ Dept of Internal Medicine II, Division of Cardiology, Medical University of Vienna, Vienna, Austria. ${ }^{3}$ Center for Global Health and Diseases, PAHO/WHO Collaborating Centre for Research and Training for Schistosomiasis Elimination, Case Western Reserve University School of Medicine, Cleveland, OH, USA. ${ }^{4}$ Faculté de Médecine, Université Paris-Sud and Université Paris-Saclay, Le Kremlin-Bicêtre, France. ${ }^{5}$ INSERM UMR_S 999, Le Plessis-Robinson, France. ${ }^{6}$ AP-HP, Service de Pneumologie, Centre de Référence de l'Hypertension Pulmonaire Sévère, DHU Thorax Innovation, Hôpital de Bicêtre, Le Kremlin-Bicêtre, France. ${ }^{7}$ Dept of Clinical Research, London School of Hygiene and Tropical Medicine, London, UK.

Correspondence: Christian Gerges, Dept of Medicine II, Division of Cardiology, Medical University of Vienna, Währinger Gürtel 18-20, 1090 Vienna, Austria. E-mail: christian.gergesameduniwien.ac.at

@ERSpublications

Sch-PAH and iPAH share common pathophysiological mechanisms related to inflammation and the TGF- $\beta$ signalling pathway. Sch-PAH patients show a significantly better haemodynamic profile and survival than iPAH patients. http://bit.ly/2mNwzWZ

Cite this article as: Knafl D, Gerges $\mathrm{C}$, King $\mathrm{CH}$, et al. Schistosomiasis-associated pulmonary arterial hypertension: a systematic review. Eur Respir Rev 2020; 29: 190089 [https://doi.org/10.1183/16000617.00892019].

ABSTRACT Schistosomiasis-associated pulmonary arterial hypertension (Sch-PAH) is a life-threatening complication of chronic hepatosplenic schistosomiasis. It is suggested to be the leading cause of pulmonary arterial hypertension (PAH) worldwide. However, pathophysiological data on Sch-PAH are scarce. We examined the hypothesis that there are pronounced similarities in pathophysiology, haemodynamics, and survival of Sch-PAH and idiopathic PAH (iPAH).

This systematic review and meta-analysis was registered in the PROSPERO database (identifier CRD42018104066). A systematic search and review of the literature was performed according to PRISMA guidelines for studies published between 01 January 1990 and 29 June 2018.

For Sch-PAH, 18 studies evaluating pathophysiological mechanisms, eight studies on haemodynamics $(n=277)$, and three studies on survival $(n=191)$ were identified. 16 clinical registries reporting data on haemodynamics and survival including a total of 5792 patients with iPAH were included for comparison. Proinflammatory molecular pathways are involved in both Sch-PAH and iPAH. The transforming growth factor (TGF)- $\beta$ signalling pathway is upregulated in Sch-PAH and iPAH. While there was no difference in mean pulmonary artery pressure $(54 \pm 17 \mathrm{mmHg}$ versus $55 \pm 15 \mathrm{mmHg}, \mathrm{p}=0.29)$, cardiac output $\left(4.4 \pm 1.3 \mathrm{~L} \cdot \mathrm{min}^{-1}\right.$ versus $\left.4.1 \pm 1.4 \mathrm{~L} \cdot \mathrm{min}^{-1}, \mathrm{p}=0.046\right)$, and cardiac index $\left(2.6 \pm 0.7 \mathrm{~L} \cdot \mathrm{min}^{-1} \cdot \mathrm{m}^{-2}\right.$ versus $\left.2.3 \pm 0.8 \mathrm{~L} \cdot \mathrm{min}^{-1} \cdot \mathrm{m}^{-2}, \mathrm{p}<0.001\right)$ were significantly higher in Sch-PAH compared to $\mathrm{PAH}$, resulting in a lower pulmonary vascular resistance in Sch-PAH ( $10 \pm 6$ Woods units versus $13 \pm 7$ Woods units, $\mathrm{p}<0.001)$. 1 - and 3-year survival were significantly better in the Sch-PAH group $(\mathrm{p}<0.001)$.

Sch-PAH and $\mathrm{PAH}$ share common pathophysiological mechanisms related to inflammation and the TGF- $\beta$ signalling pathway. Patients with Sch-PAH show a significantly better haemodynamic profile and survival than patients with iPAH.

This article has supplementary material available from err.ersjournals.com

Submitted article, peer reviewed.

Received: 21 July 2019 | Accepted after revision: 17 Sept 2019

Copyright CERS 2020. This article is open access and distributed under the terms of the Creative Commons Attribution Non-Commercial Licence 4.0. 


\section{Introduction}

Schistosomiasis is a parasitic infection caused by trematode worms that are known to cause either acute infection (known as Katayama syndrome) or chronic infection, which primarily results from the host's immune response to schistosome eggs and the granulomatous reaction provoked by their antigens $[1,2]$. Schistosomiasis-associated pulmonary arterial hypertension (Sch-PAH) is a life-threatening complication of chronic hepatosplenic schistosomiasis [3-5]. Schistosomiasis pertains to neglected tropical diseases, which affect a large number of people and usually attract insufficient attention, research efforts and financial resources, since neglected tropical diseases primarily concern people of lower socioeconomic status [6]. Hereby, schistosomiasis affects more than 230 million people worldwide, of whom 10\% develop hepatosplenic disease [7-9]. Of these, 5\% may develop pulmonary arterial hypertension (PAH), suggesting schistosomiasis to be the leading cause of $\mathrm{PAH}$ worldwide $[3,5,10,11]$. Recent data even indicate that these numbers are an underestimation of the actual burden of disease [7, 12-14]. Extrapolating the data from a prevalence study suggests that there are likely to be a total of 425000 patients with Sch-PAH worldwide $[4,15]$. In contrast, idiopathic PAH (iPAH) is rare, with a prevalence of 6-10 per million in the western world and 15-25 per million for idiopathic, familial, drug-induced and associated PAH [16]. To date, Schistosoma mansoni is known to be the primary cause of Sch-PAH, while only a few cases of PAH caused by other schistosomal species have been reported in the literature [17]. In addition, recent preliminary data suggest that Schistosoma japonicum may induce PAH in mice [18].

Despite its high prevalence compared to $\mathrm{iPAH}$, relatively little is known about the underlying pathophysiological mechanisms of Sch-PAH [11]. The following non-mutually exclusive aetiologies have been proposed: 1) mechanical obstruction of the pulmonary circulation by worm eggs; 2) inflammation leading to endothelial cell dysfunction due to the passage of worms or eggs; and 3) portal hypertension leading to pulmonary overflow and thereby endothelial cell dysfunction, comparable with portopulmonary hypertension [11, 19-21]. Compared to Sch-PAH, iPAH has been studied in considerably more detail. For patients with $\mathrm{iPAH}$, targeted therapy is available and effective, whereas there is no targeted treatment approved for Sch-PAH [22]. The anthelmintic drug praziquantel kills adult worms, but is ineffective against immature parasites or eggs. In addition, it has been suggested that treatment of murine Sch-PAH with praziquantel has the potential to reverse vascular remodelling, including obliterative lesions $[5,23]$. The vascular remodelling present in Sch-PAH has a point of no return, beyond which, anthelmintic therapies are ineffective to prevent progression to $\mathrm{PAH}[20]$.

The histopathologic changes found in the pulmonary vasculature of Sch-PAH are similar to those found in iPAH $[3,24,25]$. Therefore, it has been hypothesised that similar pathophysiological mechanisms are involved in both types of PAH [20, 24].

Understanding the underlying pathophysiologic mechanisms of Sch-PAH in comparison to iPAH may allow future modulation of these pathways with novel targeted therapies [26]. To our knowledge, this is the first systematic review and meta-analysis comparing pathophysiological mechanisms, haemodynamics and survival of patients with Sch-PAH and iPAH.

\section{Methods}

Full methodological details are available in the online supplement.

\section{Results}

Our database search delivered a total of 533 unique records. Overall, 250 records were excluded after screening of titles and abstracts, resulting in 283 unique papers for full text review. In addition, we identified 17 relevant studies from bibliographies of relevant publications (figure 1).

\section{Pathophysiologic mechanisms in Sch-PAH and iPAH}

A total of 18 studies examining the pathophysiological mechanisms of Sch-PAH were eligible for inclusion (table E2) [3, 25, 28-42]. Mechanisms involved in the pathogenesis of iPAH were selected from the proceedings of the 6th World Symposium on Pulmonary Hypertension and compared to pathophysiologic pathways in Sch-PAH (table 1 and figure 2) [74]. No valid studies were found on the following 10 molecules regarding their involvement in the development of Sch-PAH: endothelin-1; prostacyclin; $\left[\mathrm{K}^{+}\right]$channels; macrophage inflammatory protein-1 $\alpha$; von Willebrand factor; matrix metalloproteinase (MMP)-2; membrane-type-MMP1; tissue inhibitor of MMP-1; serotonin transporter/receptor; and chemokine (C-C motif) ligand 5.

Transforming growth factor (TGF)- $\beta$ isoforms 1,2 , and 3 are expressed in pulmonary hypertension arteries [43, 67]. TGF- $\beta 1$ enhances cell proliferation in smooth muscle cells (SMCs) and adventitial fibroblasts in the pulmonary arteries of patients with iPAH and has a growth-inhibitory effect on normal cells $[31,43,75]$. In iPAH its expression is dysregulated, showing a loss of function for the TGF- $\beta$ family 


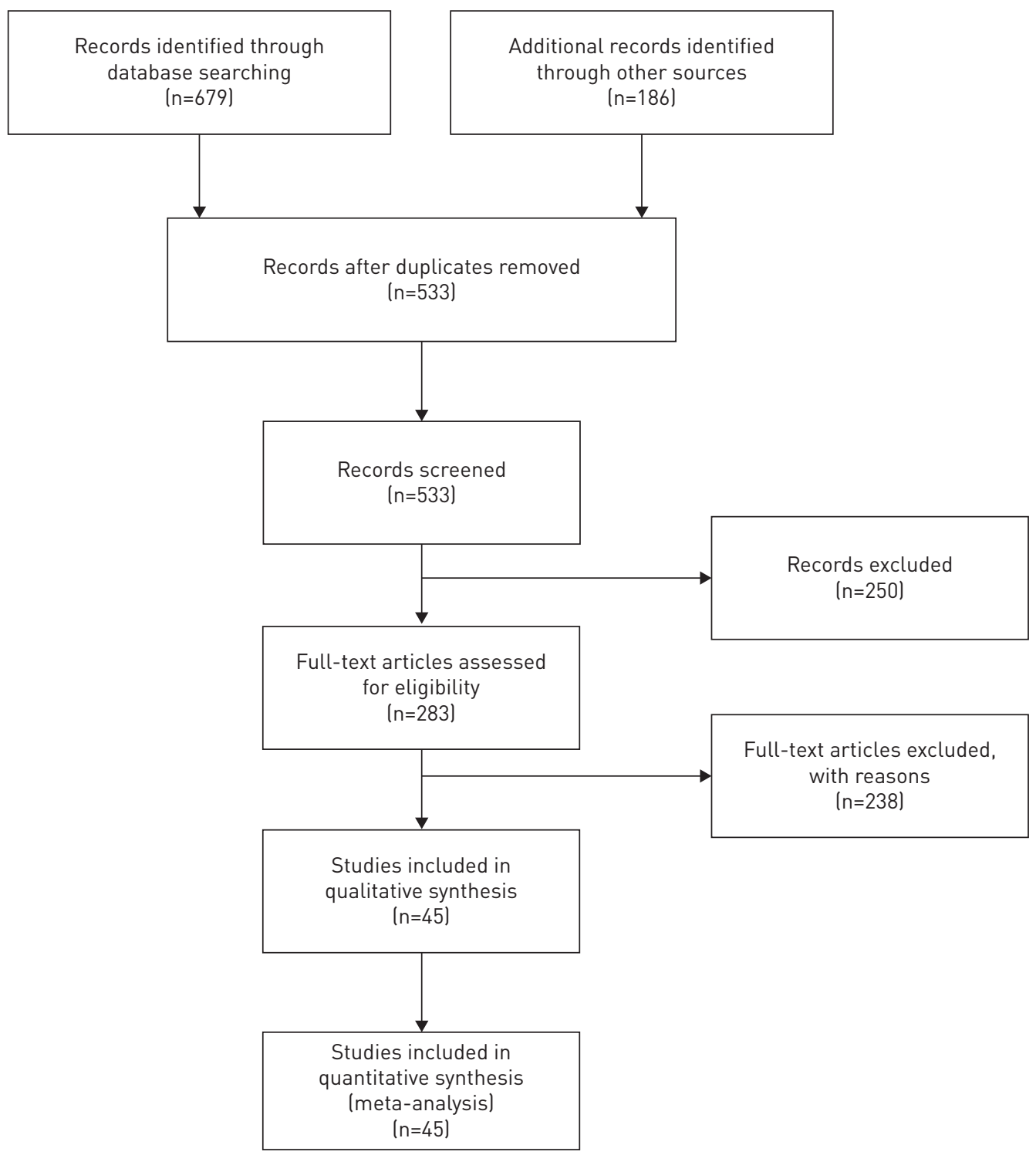

FIGURE 1 Flow diagram for search and selection of included studies [27].

signalling in endothelial cells of iPAH, but also a gain of function in SMC growth and AF activation. Patients with Sch-PAH and periportal fibrosis had significantly higher serum levels of TGF- $\beta 1$ when compared to patients with schistosomal periportal fibrosis only [31]. Furthermore, TGF- $\beta 1$ and Smad2/ 3-dependent TGF- $\beta$ signalling are mandatory for the pathogenesis of experimental pulmonary hypertension caused by S. mansoni [35]. GRAHAM et al. [35] demonstrated a significant increase in the level of TGF- $\beta 1$ mRNA in $S$. mansoni-exposed mice compared to unexposed mice. However, there were no changes in TGF- $\beta 2$ or TGF- $\beta 3$ expression between the exposed and the unexposed group. The study also showed the increase in TGF- $\beta 1$ to be dependent on the T-helper (Th) 2 cytokines interleukin (IL)- 4 and IL-13, which are induced by $S$. mansoni. Neutralisation of all TGF- $\beta$ isoforms with anti-pan-TGF- $\beta$ neutralising antibody resulted in partial protection against increases in right ventricular systolic pressure (RVSP) and media thickening induced by S. mansoni exposure [35]. No significant changes in intima thickness, right ventricular hypertrophy and peri-egg granuloma volume were observed. The same occurred when the effect of blockade of TGF- $\beta$ receptor-1 kinase activity in $S$. mansoni-exposed mice was tested: the inhibitors partially prevented the increase in RVSP, but not of medial thickening. In addition, the amounts of IL-4 and IL-13 mRNA were significantly increased after exposure to $S$. mansoni, but trended towards suppression, when inhibited with anti-pan-TGF- $\beta$ antibody [35]. These findings, taken together with previously described increased TGF- $\beta$ signalling in Schistosoma-infected mice lacking the decoy IL-13 receptor IL-13R $\alpha 2$, point towards a mutually amplifying feed-forward loop of IL-4/IL-13 and 
TABLE 1 Comparison of pathophysiological mechanisms in idiopathic pulmonary arterial hypertension (iPAH) and schistosomiasis-associated pulmonary arterial hypertension (Sch-PAH)

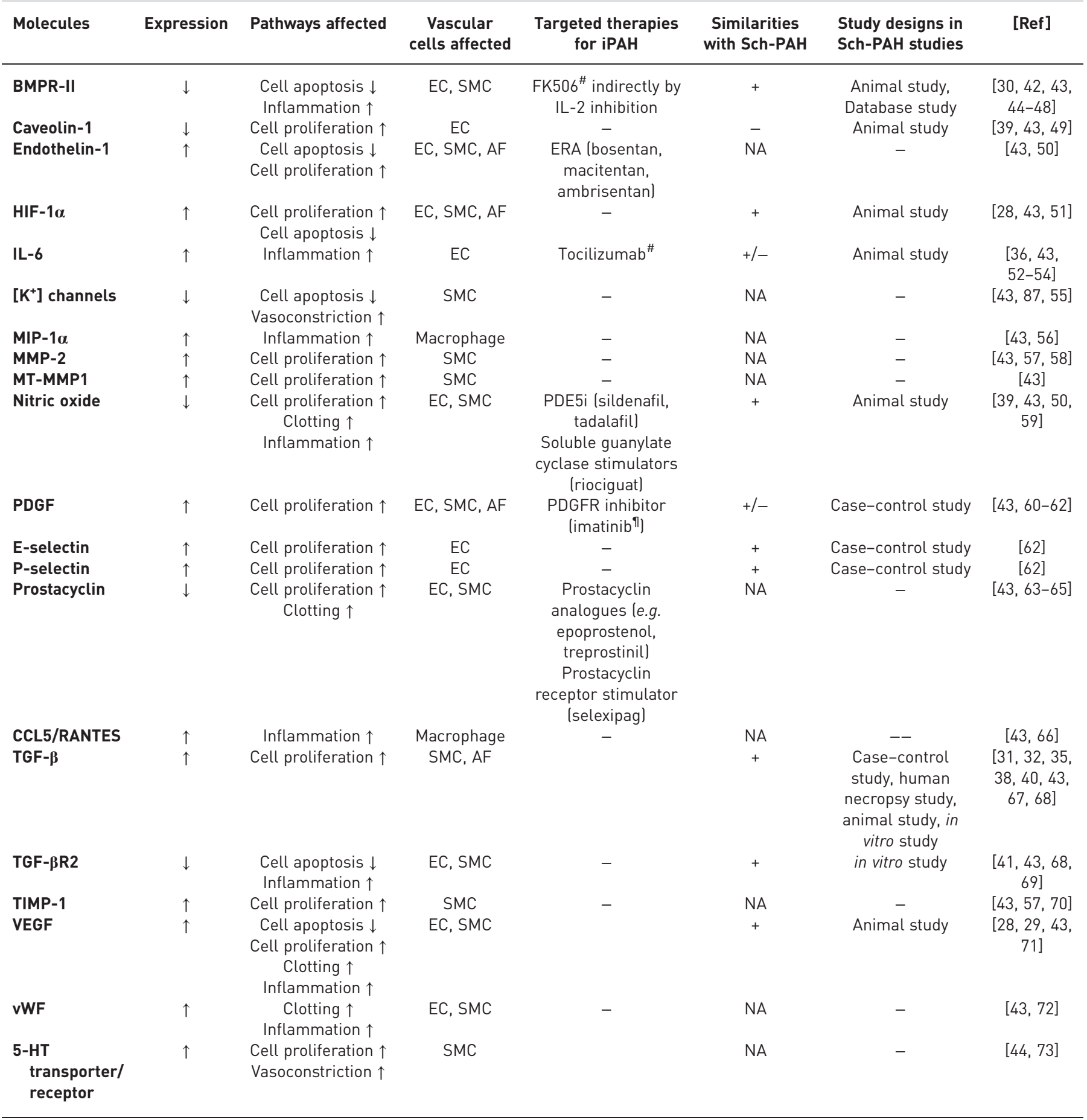

Selected pathophysiological patterns for iPAH as presented at WSPH 2018 [42], sought for similarities in Sch-PAH. BMPR-II: bone morphogenetic protein receptor type 2; HIF-1 $\alpha$ : hypoxia-inducible factor $1-\alpha$; IL: interleukin; MIP-1 $\alpha$ : macrophage inflammatory protein $1-\alpha$; MMP-2: matrix metalloproteinase-2; MT-MMP1: membrane-type MMP-1; PDGF: platelet-derived growth factor; TGF- $\beta$ : transforming growth factor $\beta$; TGF- $\beta R_{2}$ : transforming growth factor $\beta$ receptor 2; TIMP-1: tissue inhibitor of metalloproteinases-1; VEGF: vascular endothelial growth factor; vWF: von Willebrand factor; 5-HT: serotonin; EC: endothelial cell; SMC: smooth muscle cell; AF: adventitial fibroblast; ERA: endothelin receptor antagonist; PDE5i: phosphodiesterase-5 inhibitor; NA: not applicable. -: different in iPAH and Sch-PAH; +: similar in iPAH and Sch-PAH. ${ }^{\#}$ : drugs currently under investigation, that are not yet approved for therapy of iPAH; ${ }^{\text {? }}$ : negative trials in humans. Data from [43]. 


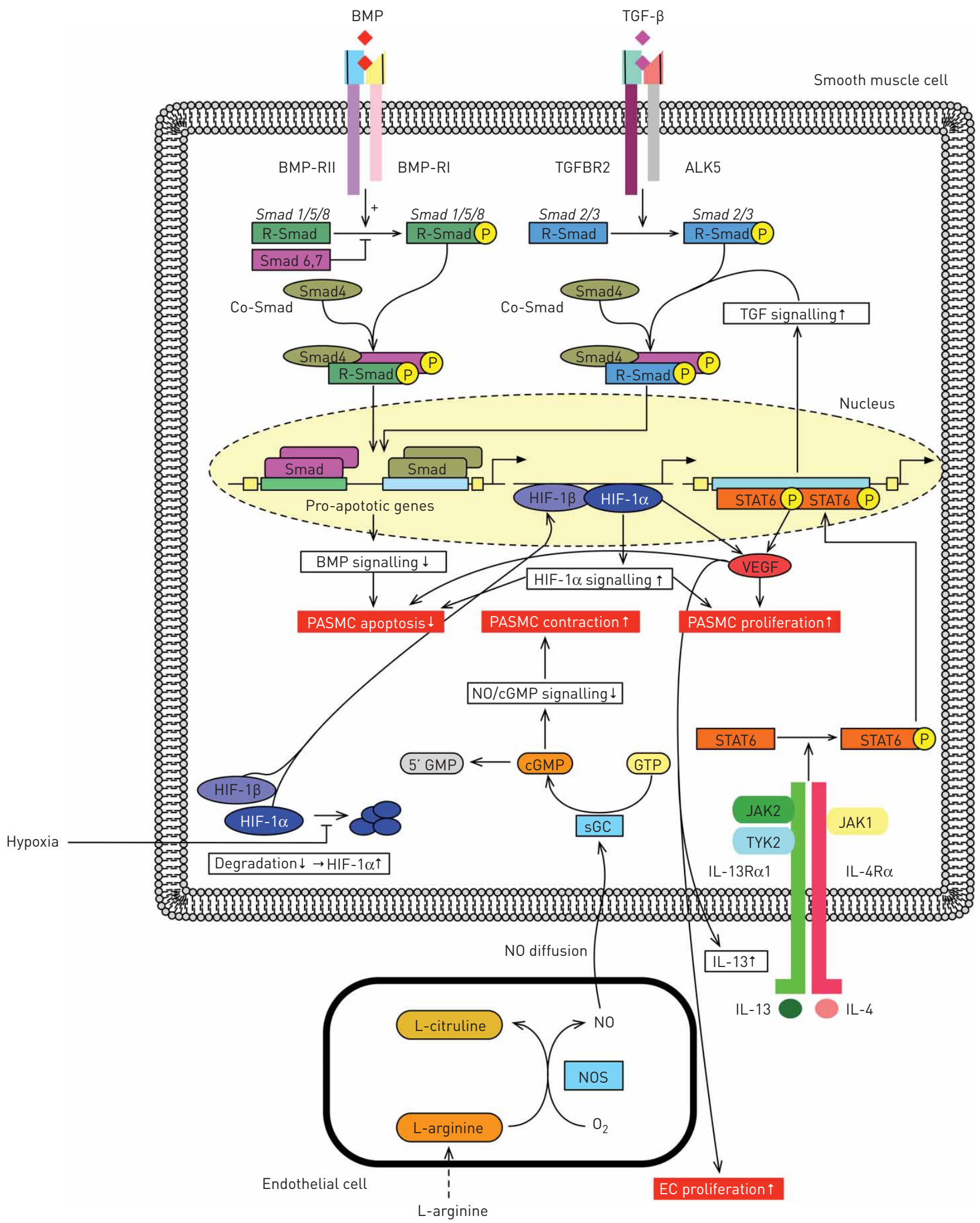

FIGURE 2 Main pathophysiologic pathways in schistosomiasis-associated pulmonary arterial hypertension (Sch-PAH). Schematic diagram depicting the main pathophysiologic mechanisms involved in Sch-PAH, which have been described previously in idiopathic pulmonary arterial hypertension. ALK: activin receptor-like kinase; BMP: bone morphogenetic protein; BMP-R: bone morphogenetic protein receptor; cGMP: cyclic guanosine monophosphate; EC: endothelial cell; GMP: guanosine monophosphate; GTP: guanosine triphosphate; HIF: hypoxia-inducible factor; IL: interleukin; IL-13R: IL-13 receptor; IL-4R: IL-4 receptor; JAK: Janus kinase; NO: nitric oxide; NOS: nitric oxide synthase; PASMC: pulmonary arterial smooth muscle cell; sGC: soluble guanylate cyclase; STAT: signal transducer and activator of transcription; TGF- $\beta$ : transforming growth factor $\beta$; TGF- $\beta$ R: TGF- $\beta$ receptor; TYK: tyrosine kinase; VEGF: vascular endothelial growth factor. 
TGF- $\beta[33,35]$. Recent data emphasise the importance of the activation of TGF- $\beta$ by thrombospondin (TSP)-1 in the development of experimental pulmonary hypertension caused by S. mansoni [38]. TSP-1 is upregulated in the lungs of mice after exposure to $S$. mansoni, via recruitment of circulating monocytes, while TSP-1 inhibition or knockout hinders activation of TGF- $\beta$ and protects against pulmonary hypertension [38].

Another component of the TGF- $\beta$-related family is the BMPR2 gene, coding for bone morphogenetic protein (BMP) receptor type 2 (BMPR-II), which exhibits heterozygous germline mutations in $70-80 \%$ of familial cases of PAH [43-45]. Furthermore, BMPR-II expression is reduced in plexiform lesions and remodelled pulmonary arteries, especially in endothelial cells of patients with iPAH [43,46]. Recent data indicate that cells in the central core of plexiform lesions lack TGF- $\beta$ and BMP signalling, which would allow plexiform lesions to abnormally proliferate (via loss of cytostatic TGF- $\beta$ signalling), or facilitate apoptosis of endothelial cells (via loss of BMPR-II) [43]. In addition, it has become clear that BMPR2 mutations in SMCs contribute to abnormal growth responses to BMP and TGF- $\beta$ [76]. Reduced BMPR-II expression leads to exaggerated TGF- $\beta$ signalling and altered cellular responses to TGF- $\beta$, with the Smad pathway being the mechanism in common of BMP and TGF- $\beta$ [76]. The combination of SMC proliferation and increased endothelial cell apoptosis has been proposed to be an important mechanism for the development of PAH [76]. In experimental pulmonary hypertension caused by S. mansoni, loss of BMPR-II has shown to be associated with a higher degree of pulmonary vascular remodelling, which could be shown in heterozygous mice with a null BMPR2 mutation $\left(B M P R 2^{+/-}\right)[30,35]$. Moreover, $B M P R 2^{+/-}$mice appeared to have an increased pulmonary egg burden and higher cytokine expression in their lungs compared to wild-type mice [30]. A database study, that analysed RNA-seq data from whole lung tissue of mice with experimental pulmonary hypertension caused by S. mansoni (GSE49114), also concluded BMPR-II, besides Smad9, Eng, and IL-4, to be of importance in the development of pulmonary hypertension [42].

Furthermore, it has been proposed that plexiform lesions represent a process of misguided angiogenesis based on findings in the expression of vascular endothelial growth factor (VEGF), its receptors and hypoxia-inducible factor (HIF)- $1 \alpha$ and HIF-1ß [51]. In iPAH, VEGF is among the factors that are suspected to enhance endothelial cell and SMC proliferation, or decrease apoptosis [51]. VEGF is induced by the Th2 inflammatory cytokines IL- 4 and IL-13 and can contribute to Th2 responses by forming a proinflammatory feed-forward loop. Thereby VEGF plays an important role in the development of Sch-PAH [37, 77]. In a murine model of pulmonary hypertension caused by S. mansoni, CHABON et al. [29] were able to show that VEGF blockade with a VEGF receptor/tyrosine kinase inhibitor (SU5416) was not only able to partially suppress the expression of IL-4 and IL-13 in lung and liver of infected mice, but also inhibit pulmonary vascular remodelling. Furthermore, an animal model conducted by ARAúJO et al. [28] showed with the use of the hypoxia marker pimonidazole, that hypoxia occurred in inflammatory cells around eggs and granulomas in liver, spleen and lungs of mice infected with S. mansoni. In addition, positive VEGF and HIF- $1 \alpha$ immunostaining were observed in inflammatory regions. However, the study failed to verify a correlation between pimonidazole binding (100\% positive) and HIF-1 $\alpha$ (21\% positive) and VEGF expression (18\% positive) in lung tissues and granulomas. The authors hypothesised this to apply because of nonspecific damage and molecular sequelae induced by the passage of schistosomulae through pulmonary vessels in early stages of the disease [28].

Increased serum levels of the proinflammatory cytokine IL-6 have been found in patients with iPAH [52, 78]. An upregulation of the IL-6-STAT3-NFATc2 pathway has also been found in experimental models of pulmonary hypertension [79, 80]. One study utilising whole transcriptome analysis, described an upregulation of the IL-6-STAT3-NFATc2 pathway in lungs of mice exposed to S. mansoni [36]. Immunostaining revealed increased IL-6, STAT3, and NFATc2 levels in peri-egg granulomas and adventitial infiltrates. However, whole lung samples were utilised for transcriptome analysis including multiple tissue compartments like parenchyma and airways and not only vasculature, which definitely represents a major limitation of this study [36]. The same study postulated that in contrast to other models of PH, where IL-6 appears to be pathogenic, IL-6 would have protective effects against the development of experimental PH caused by S. mansoni. However, taking a closer look at the data, the authors found decreased media remodelling in mice with a genetic lack of IL-6 (IL- $6^{-/-}$mice) stimulated intraperitoneally and intravenously with eggs of S. mansoni [36]. No differences in RVSP, intima thickness, right ventricular hypertrophy, peri-egg granulomas, or clearance of eggs from the lungs between $I L-6^{-/-}$and $I L-6^{+/+}$mice were observed. Additionally, there was a broad spreading of the values of media thickness in $I L-6^{-1-}$ mice. 
evaluated in meta-analysis (table E4) [86-88]. Haemodynamic data from 11 clinical registries on iPAH, including a total of 3532 patients, were utilised for comparison (table E5) [16, 60, 81, 89-96].

Haemodynamics from single studies and grand means of all included studies in Sch-PAH are given in table E6; those for iPAH are given in table E7. A comparison of grand means in Sch-PAH and iPAH is provided in table 2.

While there was no difference in mean pulmonary arterial pressure $(54 \pm 17 \mathrm{mmHg}$ versus $55 \pm 15 \mathrm{mmHg}$, $\mathrm{p}=0.29)$, cardiac output $\left(4.4 \pm 1.3 \mathrm{~L} \cdot \mathrm{min}^{-1}\right.$ versus $\left.4.1 \pm 1.4 \mathrm{~L} \cdot \mathrm{min}^{-1}, \mathrm{p}=0.046\right)$ and cardiac index $\left(2.6 \pm 0.7 \mathrm{~L} \cdot \mathrm{min}^{-1} \cdot \mathrm{m}^{-2}\right.$ versus $\left.2.3 \pm 0.8 \mathrm{~L} \cdot \mathrm{min}^{-1} \cdot \mathrm{m}^{-2}, \mathrm{p}<0.001\right)$ were significantly higher in Sch-PAH compared to iPAH and pulmonary vascular resistance was thus significantly lower in Sch-PAH

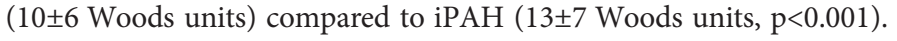

\section{Survival in Sch-PAH and IPAH}

Three studies on survival in Sch-PAH, including 191 patients, were identified (table E8) [15, 81, 82]. For comparison, 11 clinical registries including a total of $3653 \mathrm{iPAH}$ patients were used (table E9) [60, 81, 91, 93, 94, 96-101].

1 -year survival was significantly better in the Sch-PAH group $(91 \pm 9.9 \%)$ compared to iPAH $(86.1 \pm 9.7$, $\mathrm{p}<0.001)$. The same differential applied for 2 -year survival $(84.3 \pm 20.8 \%$ versus $75.7 \pm 11.7 \%, \mathrm{p}<0.001)$ and 3 -year survival $(73 \pm 26.8 \%$ versus $67.3 \pm 14.1 \%, \mathrm{p}<0.001)$ (table 3 ).

5 -year survival was significantly better in Sch-PAH (52.5 \pm 19.9 versus $79.0 \pm 14.1, \mathrm{p}<0.001)$. However, only one study assessed 5-year survival in Sch-PAH (tables E8) [82]. This study evaluated the effect of $\mathrm{PAH}$-targeted therapies on survival in Sch-PAH. Of note, survival at 5 years was significantly better in those receiving targeted therapies $(69.2 \%$ versus $89.1 \%, \mathrm{p}=0.029)$.

\section{Discussion}

Schistosomiasis-associated PAH is a prevalent and life-threatening disease, with a high socioeconomic burden. Still, Sch-PAH is relatively understudied and data on the effect of schistosomiasis on the pulmonary vasculature are scarce. Therefore, we decided to perform this systematic review and meta-analysis, which sought to compare pathophysiologic patterns, haemodynamics, and survival of patients with Sch-PAH and iPAH from the existing data. Following an extensive search, 29 relevant papers on Sch-PAH were identified. Compared to $\mathrm{iPAH}$, only few data were available on the pathophysiological mechanisms of Sch-PAH. Nevertheless, multiple underlying pathological mechanisms present in iPAH could also be confirmed for Sch-PAH. Furthermore, both entities showed histological similarities and identical plexogenic arteriopathy in lung samples taken at autopsy [3]. Our data show that patients with Sch-PAH have a more favourable haemodynamic profile and longer survival compared to iPAH, even in the absence of targeted therapy.

FERNANDEs et al. [82] compared the survival of 102 newly diagnosed patients with Sch-PAH treated with PAH-targeted therapies against a group of 50 untreated patients from a historical cohort. The 5-year survival of the untreated group was $69.2 \%$, compared to $89.1 \%$ in the treated Sch-PAH group ( $\mathrm{p}=0.029$ ), showing that the use of targeted PAH therapy was associated with improved survival [82].

TABLE 2 Comparison of haemodynamics of patients with schistosomiasis-associated pulmonary arterial hypertension (Sch-PAH) and (idiopathic pulmonary arterial hypertension) iPAH

\begin{tabular}{|c|c|c|c|c|c|}
\hline \multirow[t]{2}{*}{ Haemodynamic variable } & \multicolumn{2}{|c|}{ Sch-PAH } & \multicolumn{2}{|c|}{ iPAH } & \multirow[t]{2}{*}{ p-value } \\
\hline & $\mathbf{n}$ & mean士sD & $\mathbf{n}$ & mean $\pm s D$ & \\
\hline $\mathrm{CO} L \cdot \min ^{-1}$ & 181 & $4.4 \pm 1.3$ & 144 & $4.1 \pm 1.4$ & 0.046 \\
\hline $\mathrm{CI} \mathrm{L} \cdot \mathrm{min}^{-1} \cdot \mathrm{m}^{-2}$ & 104 & $2.6 \pm 0.7$ & 3388 & $2.3 \pm 0.8$ & $<0.001$ \\
\hline mRAP mmHg & 277 & $11 \pm 5$ & 3532 & $10 \pm 6$ & 0.007 \\
\hline mPAP mmHg & 277 & $54 \pm 17$ & 3532 & $55 \pm 15$ & 0.290 \\
\hline mPAWP mmHg & 193 & $12 \pm 4$ & 3142 & $10 \pm 4$ & $<0.001$ \\
\hline PVR WU & 277 & $10 \pm 6$ & 1396 & $13 \pm 7$ & $<0.001$ \\
\hline
\end{tabular}

CO: cardiac output; $\mathrm{Cl}$ : cardiac index; mRAP: mean right atrial pressure; mPAP: mean pulmonary artery pressure; mPAWP: mean pulmonary arterial wedge pressure; PVR: pulmonary vascular resistance. Bold in p-values idicates significance. 
TABLE 3 Comparison of survival of patients with schistosomiasis-associated pulmonary arterial hypertension (Sch-PAH) and idiopathic pulmonary arterial hypertension (iPAH)

\begin{tabular}{|c|c|c|c|c|c|}
\hline \multirow[t]{2}{*}{ Survival } & \multicolumn{2}{|c|}{ Sch-PAH } & \multicolumn{2}{|c|}{ iPAH } & \multirow[t]{2}{*}{ p-value } \\
\hline & $\mathbf{n}$ & mean $\pm s D$ & $\mathrm{n}$ & mean $\pm s D$ & \\
\hline 1-year & 191 & $91.0 \pm 9.9$ & 3653 & $86.1 \pm 9.7$ & $<0.001$ \\
\hline 2-year & 191 & $84.3 \pm 20.8$ & 1644 & $75.7 \pm 11.7$ & $<0.001$ \\
\hline 3-year & 191 & $73.0 \pm 26.8$ & 3653 & $67.3 \pm 14.1$ & $<0.001$ \\
\hline 5-year & 102 & $79.0 \pm 14.1$ & 2630 & $52.5 \pm 19.9$ & $<0.001$ \\
\hline
\end{tabular}

Based on an absence of a positive acute response to vasoreactivity testing in Sch-PAH [15, 102], as usually observed in $\sim 15 \%$ of patients with iPAH, it has been previously hypothesised that Sch-PAH and portopulmonary hypertension might share pathophysiologic mechanisms [15].

Previous studies have described egg deposition in lung vessels as a key mechanism in the development of pulmonary vascular disease and PAH. Recently, however, GraHAm et al. [34] have illustrated, via the detection of $S$. mansoni soluble egg antigen in 18 lung samples collected from necropsy of patients with Sch-PAH, that it was unlikely to detect a significant amount of persistent parasite-derived antigens within the lungs of those individuals. In this study, all lung samples showed histological evidence of pulmonary vascular remodelling with plexiform lesions (100\%) and medial thickening (89\%) [34]. Pulmonary granulomas were found in only $22 \%$ of patients [34]. None of the 18 lungs showed visible eggs, or positive immunofluorescence staining for soluble egg antigen [34]. This is in contrast to historical data on human autopsy studies in Sch-PAH, which reported schistosomal eggs in $100 \%$ of lung samples, and an animal study by CRosby et al. [25] which showed that only mice with lung egg burden developed pulmonary hypertension [103]. Another animal study showed that the development of pulmonary hypertension could be prevented by the use of praziquantel, and that established vascular remodelling could be reversed [25]. These findings are controversial with respect to Sch-PAH in humans, where inflammation and vascular lesions are persistent in individuals who died from Sch-PAH despite the lack of soluble egg antigen in lung samples collected at autopsy [34]. Graham et al. [34] hypothesised that the absence of eggs in their study (compared to historical reports) derived from the introduction of anthelmintic treatment with praziquantel. The authors argue that after an initial acute inflammatory response, vascular lesions are established, which persist beyond a "point of no return", progressing to PAH through altered cellular mechanisms and clonal proliferation [34, 43].

MAUAD et al. [3] compared lung tissue samples collected at autopsy of patients who died from Sch-PAH or $\mathrm{iPAH}$ and found both entities to be histologically indistinguishable, with both featuring plexogenic arteriopathy as the predominant pattern of pulmonary vasculopathy. Lymphocytic vasculitis with perivascular inflammatory infiltrates of B-cells, T-cells and mast cells was equally present in iPAH and Sch-PAH samples. The presence of $S$. mansoni eggs could only be observed in two out of 10 cases, which were both associated with active intestinal infection [3].

Overall, it appears that iPAH and Sch-PAH show pronounced similarities in their underlying molecular pathogenic mechanisms: reduced BMPR-II signalling contributes to abnormal growth responses to BMP and TGF- $\beta$, leading to a combination of SMC proliferation and increased endothelial cell apoptosis in iPAH [76]. In experimental pulmonary hypertension caused by S. mansoni, loss of BMPR-II is associated with more severe pulmonary vascular remodelling [30, 35]. VEGF enhances SMC and endothelial cell proliferation through increased apoptotic resistance in iPAH [51]. Blockade of VEGF-signalling in murine pulmonary hypertension caused by S. mansoni inhibits pulmonary vascular remodelling [29]. Increased serum levels of IL-6 have been found in patients with iPAH alongside an upregulation of the IL-6-STAT3-NFATc2 pathway in experimental models of pulmonary hypertension [52, 79, 80]. In addition, deficiency of IL-6 in an IL-6 knockout mouse model was shown to be protective against the development of hypoxia-induced pulmonary hypertension compared to wild-type mice [104]. In contrast, one study elucidated that mice lacking IL-6 developed pulmonary hypertension, which was associated with significant intima remodelling without increase in media thickness after S. mansoni exposure [36]. However, the same study reported an upregulation of the IL-6-STAT3-NFATc2 pathway in the lungs of mice exposed to S. mansoni. These contradictory findings could be context-dependent, depending on the inflammatory aetiology of pulmonary hypertension versus hypoxia-induced PH. In conclusion, it appears that data on IL-6 regulation in Sch-PAH is contradictory and that further animal and in vivo investigations are needed in the future. 
In iPAH, TGF- $\beta 1$ is dysregulated and increases cell proliferation of SMC and adventitial fibroblasts, while showing a loss of function in endothelial cells $[31,43,75]$. Patients with Sch-PAH and periportal fibrosis exhibit significantly higher TGF- $\beta 1$ serum levels than patients with schistosomal periportal fibrosis only $(p=0.006)$ [31]. Furthermore, TGF- $\beta 1$ expression is enhanced in mice exposed to S. mansoni [33, 35]. Neutralisation of all TGF- $\beta$ isoforms leads to partial protection against increases in RVSP and media thickening induced by S. mansoni exposure, with the Th2 cytokines IL-4 and IL-13 playing a role [35].

Parasitic TGF- $\beta$ superfamily members, such as Smad4 are involved in diverse developmental processes in different tissues and different stages throughout the parasite life cycle [40]. Whether these parasitic TGF- $\beta$ superfamily members, such as S. mansoni inhibin/activin, which is abundantly expressed in ovipositing females and eggs, play a major role in the development of Sch-PAH needs to be determined in future studies [32]. Nevertheless, it has been demonstrated that the schistosomal type II receptor strongly binds human TGF- $\beta$, which gives strong evidence for the utilisation of a host ligand in the parasite's growth and development; however, which does not rule out the involvement of a schistosomal self-ligand [41].

It therefore appears that the infringing underlying mechanisms in Sch-PAH and $\mathrm{PAH}$ eventually result in a similarly exaggerated response to injury or chronic inflammatory stimuli (i.e. overstimulated or aberrant wound-healing mechanisms). TGF- $\beta 1$ is known to function as the profibrotic growth factor in wound healing. Under normal wound-healing conditions TGF- $\beta 1$ enhances SMC and adventitial fibroblast proliferation and usually induces apoptosis in endothelial cells, while VEGF protects endothelial cells from apoptosis. In Sch-PAH, significantly higher TGF- $\beta 1$-serum levels have been found compared to patients with schistosomiasis without PAH. We assume that in the pulmonary arteries of patients with Sch-PAH, inadequate SMC proliferation caused by dysregulated TGF- $\beta 1$ stimulation occurs, which is reflected in the typical media thickening and intima proliferation found in histological samples of patients with Sch-PAH. In addition, SMC proliferation is further enhanced by BMPR2 mutation in SMC as mentioned above [76]. Intact BMPR2 signalling seems to be necessary for the execution of normal pulmonary vascular wound healing by the prevention of apoptosis-induced compensatory cell proliferation [105].

The limitations of this meta-analysis include the imbalance of group sizes between Sch-PAH and iPAH, as only a few data on invasive haemodynamic measurements and survival in Sch-PAH are available. Furthermore, several retrospective clinical studies had to be included for meta-analysis of Sch-PAH, due to the pronounced lack of prospective clinical data on Sch-PAH, and were compared to data on iPAH, which were derived from national registries. In addition, there was a heterogeneity in selected studies on Sch-PAH, as some studies evaluated consecutive cases while others included only newly diagnosed cases, which could have contributed to a seemingly more benign course of disease in Sch-PAH. This issue, however, has also been elicited by the scarcity of haemodynamic data by right heart catheterisation in Sch-PAH. Furthermore, meta-analysis of survival data may be biased by retrospective data and uncontrolled treatments. Additionally, the vast majority of patients with iPAH included in national registries received $\mathrm{PAH}$-specific treatments, while only a small proportion of patients with Sch-PAH were treated. We speculate that survival in Sch-PAH may therefore be underestimated. Unfortunately, the pathophysiological assessment of Sch-PAH is primarily taken from animal or in vitro studies, whereas human patient data are limited. In addition, the majority of included publications were from centres based in Brazil, as very few studies were found from other parts of the world where schistosomiasis is endemic. Publication bias, favouring the publication of positive studies, also cannot be excluded.

\section{Conclusions}

Patients with Sch-PAH show a more favourable haemodynamic profile and better survival compared to those with iPAH. Pathophysiologic mechanisms in Sch-PAH and $\mathrm{PAH}$ show pronounced molecular similarities with increased TGF- $\beta$ signalling playing a key role in both entities. Down regulation of BMPR-II, TGF- $\beta$ R2 and upregulation of HIF- $1 \alpha$, IL-13, VEGF and TGF- $\beta$ are involved in both Sch-PAH and $\mathrm{iPAH}$ (figure 2). Available data on $\mathrm{PAH}$-targeted therapies in patients with Sch-PAH suggest a beneficial effect on survival but these are scarce and need further evaluation in future randomised controlled trials. Due to the paucity of evidence-based research on Sch-PAH we emphasise the importance of future clinical studies in this field.

Conflict of interest: D. Knafl has nothing to disclose. C. Gerges reports grants from Bayer HealthCare and Actelion Pharmaceuticals, during the conduct of the study; and personal fees from GlaxoSmithKline, AOPOrphan and Actelion, outside the submitted work. C.H. King has nothing to disclose. M. Humbert reports personal fees from Actelion, Bayer, GSK, Merck and United Therapeutics, during the conduct of the study. A.L. Bustinduy has nothing to disclose.

\section{References}

Ross AG, Bartley PB, Sleigh AC, et al. Schistosomiasis. N Engl J Med 2002; 346: 1212-1220.

Bethlem EP, Schettino Gde P, Carvalho CR. Pulmonary schistosomiasis. Curr Opin Pulm Med 1997; 3: 361-365. 
4 Lapa M, Dias B, Jardim C, et al. Cardiopulmonary manifestations of hepatosplenic schistosomiasis. Circulation 2009; 119: 1518-1523.

5 Crosby A, Jones FM, Kolosionek E, et al. Praziquantel reverses pulmonary hypertension and vascular remodeling in murine schistosomiasis. Am J Respir Crit Care Med 2011; 184: 467-473.

Klohe K, Amuasi J, Kaducu JM, et al. The 2017 Oslo conference report on neglected tropical diseases and emerging/re-emerging infectious diseases: focus on populations underserved. Infect Dis Poverty 2019; 8: 40. Colley DG, Bustinduy AL, Secor WE, et al. Human schistosomiasis. Lancet 2014; 383: 2253-2264.

8 Vos T, Flaxman AD, Naghavi M, et al. Years lived with disability (YLDs) for 1160 sequelae of 289 diseases and injuries 1990-2010: a systematic analysis for the Global Burden of Disease Study 2010. Lancet 2012; 380: $2163-2196$. Chitsulo L, Loverde P, Engels D. Schistosomiasis. Nat Rev Microbiol 2004; 2: 12-13.

10 Simonneau G, Gatzoulis MA, Adatia I, et al. Updated clinical classification of pulmonary hypertension. $J$ Am Coll Cardiol 2013; 62: Suppl. 25, D34-D41.

11 Fernandes C, Dias BA, Jardim CVP, et al. The role of target therapies in schistosomiasis-associated pulmonary arterial hypertension. Chest 2012; 141: 923-928.

12 Carabin H, Marshall CM, Joseph L, et al. Estimating the intensity of infection with Schistosoma japonicum in villagers of Leyte, Philippines. Part I: a Bayesian cumulative logit model. The schistosomiasis transmission and ecology project (STEP). Am J Trop Med Hyg 2005; 72: 745-753.

13 Savioli L, Hatz C, Dixon H, et al. Control of morbidity due to Schistosoma haematobium on Pemba Island: egg excretion and hematuria as indicators of infection. Am J Trop Med Hyg 1990; 43: 289-295.

14 Shane HL, Verani JR, Abudho B, et al. Evaluation of urine CCA assays for detection of Schistosoma mansoni infection in Western Kenya. PLoS Negl Trop Dis 2011; 5: e951.

15 dos Santos Fernandes CJ, Jardim CV, Hovnanian A, et al. Survival in schistosomiasis-associated pulmonary arterial hypertension. J Am Coll Cardiol 2010; 56: 715-720.

16 Humbert M, Sitbon O, Chaouat A, et al. Pulmonary arterial hypertension in France: results from a national registry. Am J Respir Crit Care Med 2006; 173: 1023-1030.

17 Bouree P, Piveteau J, Gerbal JL, et al. [Pulmonary arterial hypertension due to bilharziasis. Apropos of a case due to Schistosoma haematobium having been cured by praziquantel]. Bull Soc Pathol Exot 1990; 83: 66-71.

18 Kassa B, Kumar R, Mickael C, et al. Schistosoma japonicum can induce pulmonary hypertension in mice. Am J Respir Crit Care Med 2019; 199: A5044.

19 Pereira GA Jr, Bestetti RB, Leite MP, et al. Portopulmonary hypertension syndrome in Schistosoma mansoni. Trans R Soc Trop Med Hyg 2002; 96: 427-428.

20 Graham BB, Bandeira AP, Morrell NW, et al. Schistosomiasis-associated pulmonary hypertension: pulmonary vascular disease: the global perspective. Chest 2010; 137: Suppl. 6, 20S-29S.

21 Schwartz E. Pulmonary schistosomiasis. Clin Chest Med 2002; 23: 433-443.

22 Hoeper MM, Apitz C, Grunig E, et al. Targeted therapy of pulmonary arterial hypertension: updated recommendations from the Cologne Consensus Conference 2018. Int J Cardiol 2018; 2272S: 37-45.

23 West J. Are obliterative pulmonary vascular lesions reversible? Am J Respir Crit Care Med 2011; 184: 397-398.

24 Papamatheakis DG, Mocumbi AO, Kim NH, et al. Schistosomiasis-associated pulmonary hypertension. Pulm Circ 2014; 4: 596-611.

25 Crosby A, Jones FM, Southwood M, et al. Pulmonary vascular remodeling correlates with lung eggs and cytokines in murine schistosomiasis. Am J Respir Crit Care Med 2010; 181: 279-288.

26 Graham BB, Kumar R. Schistosomiasis and the pulmonary vasculature (2013 Grover Conference series). Pulm Circ 2014; 4: 353-362.

27 Moher D, Liberati A, Tetzlaff J, et al. Preferred reporting items for systematic reviews and meta-analyses: the PRISMA statement. PLoS Med 2009; 6: e1000097.

28 Araújo AP, Frezza TF, Allegretti SM, et al. Hypoxia, hypoxia-inducible factor-1alpha and vascular endothelial growth factor in a murine model of Schistosoma mansoni infection. Exp Mol Pathol 2010; 89: 327-333.

29 Chabon JJ, Gebreab L, Kumar R, et al. Role of vascular endothelial growth factor signaling in Schistosoma-induced experimental pulmonary hypertension. Pulm Circ 2014; 4: 289-299.

30 Crosby A, Soon E, Jones FM, et al. Hepatic shunting of eggs and pulmonary vascular remodeling in Bmpr2(+/-) mice with schistosomiasis. Am J Respir Crit Care Med 2015; 192: 1355-1365.

31 Ferreira Rde C, Montenegro SM, Domingues AL, et al. TGF beta and IL13 in Schistosomiasis mansoni associated pulmonary arterial hypertension; a descriptive study with comparative groups. BMC Infect Dis 2014; 14: 282 .

32 Freitas TC, Jung E, Pearce EJ. TGF-beta signaling controls embryo development in the parasitic flatworm Schistosoma mansoni. PLoS Pathog 2007; 3: e52.

33 Graham BB, Mentink-Kane MM, El-Haddad H, et al. Schistosomiasis-induced experimental pulmonary hypertension: role of interleukin-13 signaling. Am J Pathol 2010; 177: 1549-1561.

34 Graham BB, Chabon J, Bandeira A, et al. Significant intrapulmonary Schistosoma egg antigens are not present in schistosomiasis-associated pulmonary hypertension. Pulm Circ 2011; 1: 456-461.

35 Graham BB, Chabon J, Gebreab L, et al. Transforming growth factor-beta signaling promotes pulmonary hypertension caused by Schistosoma mansoni. Circulation 2013; 128: 1354-1364.

36 Graham BB, Chabon J, Kumar R, et al. Protective role of IL-6 in vascular remodeling in Schistosoma pulmonary hypertension. Am J Respir Cell Mol Biol 2013; 49: 951-959.

37 Kumar R, Mickael C, Chabon J, et al. The causal role of IL-4 and IL-13 in Schistosoma mansoni pulmonary hypertension. Am J Respir Crit Care Med 2015; 192: 998-1008.

38 Kumar R, Mickael C, Kassa B, et al. TGF-beta activation by bone marrow-derived thrombospondin-1 causes Schistosoma- and hypoxia-induced pulmonary hypertension. Nat Commun 2017; 8: 15494.

39 Oliveira SD, Quintas LE, Amaral LS, et al. Increased endothelial cell-leukocyte interaction in murine schistosomiasis: possible priming of endothelial cells by the disease. PloS ONE 2011; 6: e23547.

40 Osman A, Niles EG, LoVerde PT. Expression of functional Schistosoma mansoni Smad4: role in Erk-mediated transforming growth factor beta (TGF-beta) down-regulation. J Biol Chem 2004; 279: 6474-6486. 
Osman A, Niles EG, Verjovski-Almeida S, et al. Schistosoma mansoni TGF-beta receptor II: role in host ligand-induced regulation of a schistosome target gene. PLoS Pathog 2006; 2: e54.

42 Sun Y, Lin X, Li L. Identification of biomarkers for Schistosoma-associated pulmonary arterial hypertension based on RNA-Seq data of mouse whole lung tissues. Lung 2017; 195: 377-385.

43 Tuder RM, Marecki JC, Richter A, et al. Pathology of pulmonary hypertension. Clin Chest Med 2007; 28: 23-42, vii.

44 International PPH Consortium, Lane KB, Machado RD, et al. Heterozygous germline mutations in BMPR2, encoding a TGF-beta receptor, cause familial primary pulmonary hypertension. Nat Genet 2000; 26: 81-84.

45 Deng Z, Morse JH, Slager SL, et al. Familial primary pulmonary hypertension (gene PPH1) is caused by mutations in the bone morphogenetic protein receptor-II gene. Am J Hum Genet 2000; 67: 737-744.

46 Atkinson C, Stewart S, Upton PD, et al. Primary pulmonary hypertension is associated with reduced pulmonary vascular expression of type II bone morphogenetic protein receptor. Circulation 2002; 105: 1672-1678.

47 Fantozzi I, Platoshyn $\mathrm{O}$, Wong $\mathrm{AH}$, et al. Bone morphogenetic protein-2 upregulates expression and function of voltage-gated $\mathrm{K}+$ channels in human pulmonary artery smooth muscle cells. Am J Physiol Lung Cell Mol Physiol 2006; 291: L993-1004

48 Spiekerkoetter E, Sung YK, Sudheendra D, et al. Randomised placebo-controlled safety and tolerability trial of FK506 (tacrolimus) for pulmonary arterial hypertension. Eur Respir J 2017; 50; 1602449.

49 Achcar RO, Demura Y, Rai PR, et al. Loss of caveolin and heme oxygenase expression in severe pulmonary hypertension. Chest 2006; 129: 696-705.

50 Giaid A, Saleh D. Reduced expression of endothelial nitric oxide synthase in the lungs of patients with pulmonary hypertension. N Engl J Med 1995; 333: 214-221.

51 Tuder RM, Chacon M, Alger L, et al. Expression of angiogenesis-related molecules in plexiform lesions in severe pulmonary hypertension: evidence for a process of disordered angiogenesis. J Pathol 2001; 195: 367-374.

52 Humbert M, Monti G, Brenot F, et al. Increased interleukin-1 and interleukin-6 serum concentrations in severe primary pulmonary hypertension. Am J Respir Crit Care Med 1995; 151: 1628-1631.

53 Le Hiress M, Tu L, Ricard N, et al. Proinflammatory signature of the dysfunctional endothelium in pulmonary hypertension. Role of the macrophage migration inhibitory factor/CD74 complex. Am J Respir Crit Care Med 2015; 192: 983-997.

54 Humbert M, Monti G, Fartoukh M, et al. Platelet-derived growth factor expression in primary pulmonary hypertension: comparison of HIV seropositive and HIV seronegative patients. Eur Respir J 1998; 11: 554-559.

55 Remillard CV, Yuan JX. Activation of K+ channels: an essential pathway in programmed cell death. Am J Physiol Lung Cell Mol Physiol 2004; 286: L49-L67.

56 Dorfmuller P, Perros F, Balabanian K, et al. Inflammation in pulmonary arterial hypertension. Eur Respir J 2003; 22: 358-363.

57 Lepetit H, Eddahibi S, Fadel E, et al. Smooth muscle cell matrix metalloproteinases in idiopathic pulmonary arterial hypertension. Eur Respir J 2005; 25: 834-842.

58 Matsui K, Takano Y, Yu ZX, et al. Immunohistochemical study of endothelin-1 and matrix metalloproteinases in plexogenic pulmonary arteriopathy. Pathol Res Pract 2002; 198: 403-412.

59 Zhao YD, Courtman DW, Deng Y, et al. Rescue of monocrotaline-induced pulmonary arterial hypertension using bone marrow-derived endothelial-like progenitor cells: efficacy of combined cell and eNOS gene therapy in established disease. Circ Res 2005; 96: 442-450.

60 Hoeper MM, Huscher D, Ghofrani HA, et al. Elderly patients diagnosed with idiopathic pulmonary arterial hypertension: results from the COMPERA registry. Int J Cardiol 2013; 168: 871-880.

61 Ghofrani HA, Seeger W, Grimminger F. Imatinib for the treatment of pulmonary arterial hypertension. $N$ Engl $J$ Med 2005; 353: 1412-1413.

62 Lapa M, Acencio MM, Farias AQ, et al. Selectins and platelet-derived growth factor (PDGF) in schistosomiasis-associated pulmonary hypertension. Lung 2014; 192: 981-986.

63 Tuder RM, Cool CD, Geraci MW, et al. Prostacyclin synthase expression is decreased in lungs from patients with severe pulmonary hypertension. Am J Respir Crit Care Med 1999; 159: 1925-1932.

64 Tuder RM, Zaiman AL. Prostacyclin analogs as the brakes for pulmonary artery smooth muscle cell proliferation: is it sufficient to treat severe pulmonary hypertension? Am J Respir Cell Mol Biol 2002; 26: 171-174.

65 Gaine SP, Rubin LJ. Primary pulmonary hypertension. Lancet 1998; 352: 719-725.

66 Dorfmuller P, Zarka V, Durand-Gasselin I, et al. Chemokine RANTES in severe pulmonary arterial hypertension. Am J Respir Crit Care Med 2002; 165: 534-539.

67 Botney MD, Bahadori L, Gold LI. Vascular remodeling in primary pulmonary hypertension. Potential role for transforming growth factor-beta. Am J Pathol 1994; 144: 286-295.

68 Richter A, Yeager ME, Zaiman A, et al. Impaired transforming growth factor-beta signaling in idiopathic pulmonary arterial hypertension. Am J Respir Crit Care Med 2004; 170: 1340-1348.

69 Yeager ME, Halley GR, Golpon HA, et al. Microsatellite instability of endothelial cell growth and apoptosis genes within plexiform lesions in primary pulmonary hypertension. Circ Res 2001; 88: E2-E11.

70 Vieillard-Baron A, Frisdal E, Eddahibi S, et al. Inhibition of matrix metalloproteinases by lung TIMP-1 gene transfer or doxycycline aggravates pulmonary hypertension in rats. Circ Res 2000; 87: 418-425.

71 Taraseviciene-Stewart L, Kasahara Y, Alger L, et al. Inhibition of the VEGF receptor 2 combined with chronic hypoxia causes cell death-dependent pulmonary endothelial cell proliferation and severe pulmonary hypertension. FASEB J 2001; 15: 427-438.

72 Tournier A, Wahl D, Chaouat A, et al. Calibrated automated thrombography demonstrates hypercoagulability in patients with idiopathic pulmonary arterial hypertension. Thromb Res 2010; 126: e418-e422.

73 Launay JM, Herve P, Peoc'h K, et al. Function of the serotonin 5-hydroxytryptamine 2B receptor in pulmonary hypertension. Nat Med 2002; 8: 1129-1135.

74 Humbert M, Guignabert C, Bonnet S, et al. Pathology and pathobiology of pulmonary hypertension: state of the art and research perspectives. Eur Respir J 2019; 53: 1801887.

75 Morrell NW, Yang X, Upton PD, et al. Altered growth responses of pulmonary artery smooth muscle cells from patients with primary pulmonary hypertension to transforming growth factor-beta(1) and bone morphogenetic proteins. Circulation 2001; 104: 790-795. 
Morrell NW. Pulmonary hypertension due to BMPR2 mutation: a new paradigm for tissue remodeling? Proc Am Thorac Soc 2006; 3: 680-686.

Faffe DS, Flynt L, Bourgeois K, et al. Interleukin-13 and interleukin-4 induce vascular endothelial growth factor release from airway smooth muscle cells: role of vascular endothelial growth factor genotype. Am J Respir Cell Mol Biol 2006; 34: 213-218.

Tamura Y, Phan C, Tu L, et al. Ectopic upregulation of membrane-bound IL6R drives vascular remodeling in pulmonary arterial hypertension. J Clin Invest 2018; 128: 1956-1970.

Bonnet S, Rochefort G, Sutendra G, et al. The nuclear factor of activated T-cells in pulmonary arterial hypertension can be therapeutically targeted. Proc Natl Acad Sci USA 2007; 104: 11418-11423.

Courboulin A, Paulin R, Giguere NJ, et al. Role for miR-204 in human pulmonary arterial hypertension. J Exp Med 2011; 208: 535-548.

Alves JL Jr, Gavilanes F, Jardim C, et al. Pulmonary arterial hypertension in the southern hemisphere: results from a registry of incident Brazilian cases. Chest 2015; 147: 495-501.

Fernandes CJC, Piloto B, Castro M, et al. Survival of patients with schistosomiasis-associated pulmonary arterial hypertension in the modern management era. Eur Respir J 2018; 51: 1800307.

Japyassu FA, Mendes AA, Bandeira AP, et al. Hemodynamic profile of severity at pulmonary vasoreactivity test in schistosomiasis patients. Arq Bras Cardiol 2012; 99: 789-796.

Valois FM, Nery LE, Ramos RP, et al. Contrasting cardiopulmonary responses to incremental exercise in patients with schistosomiasis-associated and idiopathic pulmonary arterial hypertension with similar resting hemodynamic impairment. PloS One 2014; 9: e87699.

Hoette S, Figueiredo C, Dias B, et al. Pulmonary artery enlargement in schistosomiasis-associated pulmonary arterial hypertension. BMC Pulm Med 2015; 15: 118.

Correa Rde A, Moreira MV, Saraiva JM, et al. Treatment of schistosomiasis-associated pulmonary hypertension. J Bras Pneumol 2011; 37: 272-276.

Gavilanes F, Piloto B, Fernandes CJC. Giant pulmonary artery aneurysm in a patient with schistosomiasis-associated pulmonary arterial hypertension. J Bras Pneumol 2018; 44: 167.

Mendes AA, Japyassu FA, Roberto F, et al. Tratamento com stent em tronco de artéria coronária esquerda por compressão do tronco da artéria pulmonar em paciente com hipertensão pulmonar esquistossomótica. Rev Bras Cardiol Invasiva 2010; 18: 89-94.

Rich S, Dantzker DR, Ayres SM, et al. Primary pulmonary hypertension. A national prospective study. Ann Intern Med 1987; 107: 216-223.

Thenappan T, Shah SJ, Rich S, et al. A USA-based registry for pulmonary arterial hypertension: 1982-2006. Eur Respir J 2007; 30: 1103-1110.

Fischler M, Speich R, Dorschner L, et al. Pulmonary hypertension in Switzerland: treatment and clinical course. Swiss Med Wkly 2008; 138: 371-378.

Badesch DB, Raskob GE, Elliott CG, et al. Pulmonary arterial hypertension: baseline characteristics from the REVEAL registry. Chest 2010; 137: 376-387.

Escribano-Subias P, Blanco I, Lopez-Meseguer M, et al. Survival in pulmonary hypertension in Spain: insights from the Spanish registry. Eur Respir J 2012; 40: 596-603.

Ling Y, Johnson MK, Kiely DG, et al. Changing demographics, epidemiology, and survival of inciden pulmonary arterial hypertension: results from the pulmonary hypertension registry of the United Kingdom and Ireland. Am J Respir Crit Care Med 2012; 186: 790-796.

Baptista R, Meireles J, Agapito A, et al. Pulmonary hypertension in Portugal: first data from a nationwide registry. Biomed Res Int 2013; 2013: 489574.

Zhang R, Dai LZ, Xie WP, et al. Survival of Chinese patients with pulmonary arterial hypertension in the modern treatment era. Chest 2011; 140: 301-309.

D’Alonzo GE, Barst RJ, Ayres SM, et al. Survival in patients with primary pulmonary hypertension. Results from a national prospective registry. Ann Intern Med 1991; 115: 343-349.

Humbert M, Sitbon O, Chaouat A, et al. Survival in patients with idiopathic, familial, and anorexigen-associated pulmonary arterial hypertension in the modern management era. Circulation 2010; 122: 156-163.

Thenappan T, Shah SJ, Rich S, et al. Survival in pulmonary arterial hypertension: a reappraisal of the NIH risk stratification equation. Eur Respir J 2010; 35: 1079-1087.

Benza RL, Miller DP, Gomberg-Maitland M, et al. Predicting survival in pulmonary arterial hypertension: insights from the Registry to Evaluate Early and Long-Term Pulmonary Arterial Hypertension Disease Management (REVEAL). Circulation 2010; 122: 164-172.

Jansa P, Jarkovsky J, Al-Hiti H, et al. Epidemiology and long-term survival of pulmonary arterial hypertension in the Czech Republic: a retrospective analysis of a nationwide registry. BMC Pulm Med 2014; 14: 45.

Costa EL, Jardim C, Bogossian HB, et al. Acute vasodilator test in pulmonary arterial hypertension: evaluation of two response criteria. Vascul Pharmacol 2005; 43: 143-147.

Lopes De Faria J. Cor pulmonale in Manson's schistosomiasis. I. Frequency in necropsy material; pulmonary vascular changes caused by schistosome ova. Am J Pathol 1954; 30: 167-193.

Savale L, Tu L, Rideau D, et al. Impact of interleukin-6 on hypoxia-induced pulmonary hypertension and lung inflammation in mice. Respir Res 2009; 10: 6.

Voelkel NF, Gomez-Arroyo J, Abbate A, et al. Pathobiology of pulmonary arterial hypertension and right ventricular failure. Eur Respir J 2012; 40: 1555-1565. 